\title{
Genetic selection for lifetime reproductive performance
}

\author{
A.C. Clutter \\ Newsham Choice Cenetics, St Louis, MO USA
}

\begin{abstract}
Genetic improvement of sow lifetime reproductive performance has value from both the economic perspectives of pork producers and the pork industry, but also from the perspective of ethical and animal welfare concerns by the general public. Genetic potential for piglets produced from individual litters is a primary determinant of lifetime prolificacy, but females must be able to sustain productivity without injury or death beyond the achievement of positive net present value. Evidence exists for between-and within-line genetic variation in sow lifetime performance, suggesting that improvements may be made by both line choices and genetic selection within lines. However, some of the same barriers to accurate within-line selection that apply to individual litter traits also present challenges to genetic selection for sow lifetime prolificacy: generally low heritabilites, sex-limited expression, expression after the age that animals are typically selected, and unfavorable genetic correlations with other traits in the profit function. In addition, there is an inherent conflict within the genetic nucleus herds where selections take place between the goal of shortened generation interval to accelerate genetic progress and the expression of sow lifetime traits. A proliferation in the industry of commercial multipliers with direct genetic ties and routine record flows to genetic nucleus herds provides a framework for accurate estimates of relevant genetic variances and covariances, and estimation of breeding values for sow lifetime traits that can be used in genetic selection.
\end{abstract}

\section{Introduction}

Female prolificacy is a primary determinant of commercial success in the pork industry and, accordingly, selection for improved prolificacy has long been recognized as a high priority in pig breeding strategies (Tess et al. 1983). Due to the overhead costs of female development to an active stage of reproduction, the effects of parity on number of piglets produced, and animal welfare concerns associated with a high turnover rate for females in the breeding herd, there is significant value in improvement of sow lifetime reproductive performance in the industry, and great interest in the impact that genetic selection may have on this goal.

The amount of genetic variation in litter size traits has been well-documented and successfully exploited in experimental and commercial selection to increase the number piglets produced per litter (Rothschild \& Bidanel 1998). More recently, there have been reports of significant genetic variation in sow longevity and lifetime output (Serenius \& Stalder 2006; Arango et al. 2005) that suggest that effective selection for sow lifetime reproductive performance may be 
possible. But questions remain regarding the complete genetic covariance architecture among all economically important traits and how to optimize selection for both lifetime prolificacy and efficient market hog performance (Young et al. 1977; Rutledge 1980; Foxcroft et al. 2006). Moreover, at a practical level there is the inherent conflict between intentional replacement of breeding females in genetic nucleus herds to minimize generation interval and accelerate genetic progress, and the need to allow expression of lifetime performance of each sow if these traits are to be measured. This conflict may affect parameter estimates from commercial pig populations, and represents a significant challenge to implementation of effective commercial breeding strategies for lifetime traits.

The objectives of the present paper are to provide a brief review of the literature on sow lifetime reproduction as related to genetic selection, and to suggest a strategy for both estimation of genetic parameters and selection for sow lifetime performance in a typical commercial pig population.

\section{The economics and dynamics of sow lifetime performance}

Although the number of piglets with the potential for full market value that are produced by a sow in her lifetime is clearly an important factor in the determination of profitability, the economics of sow lifetime performance is a complex function of investment and opportunity costs, changes in biological output over time, the value of the output and the salvage value of the sow. A definition of optimum sow lifetime performance and associated optimum parity and replacement rate for commercial herds have been the focus of several studies of which a few are highlighted herein.

Stalder et al. (2003) used a deterministic model of a breed-to-wean system to identify the average parity at which a sow achieved a positive net present value (NPV). PigCHAMP records from 1996 to 2000 were used as a basis for assumptions of input costs, performance levels and output value, and sensitivity to changes in replacement gilt cost, number of live piglets born per litter, and weaned-pig price were modeled. Using the average base assumptions, a sow reached a positive NPV at parity three. Since the average parity in all reporting herds over that same time period was 3.36, the authors concluded that the average sow in an average breedto-wean system left the herd just after reaching profitability and that significant profit potential was not realized. The average parity at which positive NPV was achieved was more sensitive to a decrease in number born alive per litter and changes in weaned-pig price than changes in replacement gilt costs.

Commercial data from 32 farms in central Illinois, collected from 1995 to 2001 and including representation of eight primary genetic lines, were used to model the sensitivity of NPV of enterprise income to parity at culling, litter income per parity, and discount rates which reflect a combination of inflation, interest rates and risk (Rodriguez-Zas et al. 2003). Average parity at culling ranged from 2.95 to 4.00 across the eight genetic lines. When income per litter was assumed for all lines at either $\$ 50$ or $\$ 10$, it was impossible for a positive NPV to be achieved in any of the lines at discount rates greater than $4 \%$ and income per litter of $\$ 10$, emphasizing the need to maximize net income per litter to realize the economic benefits of longevity. When genetic lines were compared at these fixed incomes per litter, the economic advantage of lines with greater longevity was reduced as discount rates increased, but the results in general also demonstrated that herds with a greater average longevity were subject to less economic risk than those with lesser average longevity.

The commercial data reported by Rodriguez-Zas et al. (2003) were also the basis for a subsequent application of a model for optimum replacement of assets in an infinite planning 
horizon (Burt 1965) to sow replacement and salvage value scenarios in breed-to-wean systems (Rodriguez-Zas et al. 2006). The economic inputs were discount rate, building and equipment costs per sow, sow replacement costs, revenue per piglet weaned and sow salvage value. By optimization of returns in a continuous system per fixed unit of time, this approach accounted for the opportunity cost of sow space. The optimum parity at replacement using base biological and economic inputs was 5 parities when voluntary replacement rates were low and there was no sow salvage value, and 4 parities when voluntary replacement rates were high and a percentage of sows had salvage value, the latter considered most similar to typical breed-towean production. In sensitivity analyses of economic factors, sow replacement costs and salvage value had the greatest effect on optimum parity number at replacement; revenue per piglet weaned had a significant but lesser effect. Huirne et al. (1991) reported similar results from earlier application of dynamic modeling to optimization of sow replacement, both in terms of the impact of sow costs and salvage value, and the optimum parity at replacement (5.5).

Although these economic models of sow lifetime performance provide a basis for evaluation of commercial systems and guidance for the optimum emphasis to put on longevity and biological output in assessment of individual animals in the herd, solutions are clearly complex and system specific, and there remains opportunity for improvement in resolution of the tools. Considering average parity at replacement and replacement rates observed in commercial production (Stalder et al. 2004), it is clear from reported economic analyses that there is currently greater risk of lost profit due to premature removal from the herd than due to late removal from the herd (Rodriguez-Zas et al. 2006). Even though profitability in some analyses was less sensitive to number of piglets weaned per litter than to cost of gilt development, price per weaned pig and sow salvage value (e.g., Rodriguez-Zas et al. 2006), practical models will be more useful when extended to account for line differences and genetic trend in biological output. As work continues to provide effective models for system and genetic line comparisons, interactions between lines in average number of piglets per litter across parities (Moeller et al. 2004) may also be considered.

Animal welfare has also been mentioned as a justification for improving sow longevity (e.g., Stalder et al. 2004). The economic modeling work reviewed in this section focused primarily on the optimum use of voluntary culling of sows in commercial herds, in other words optimum culling of sows from the herd because of factors such as a small litter weaned or cumulative number weaned, inadequate estimated breeding value, poor rebreeding performance or simply because of age. While minimization of involuntary culling creates the greatest opportunity for optimization as defined in these economic models (i.e., the greatest opportunity for voluntary culling), it is also the minimization of involuntary culling and optimization of voluntary culling in tandem that should result in improved sow longevity from an animal welfare perspective. A short life in the herd that concludes with voluntary culling because of a small litter produced contributes to a need for more animals to produce the same amount of output and for that reason is undesirable from both an economic and animal welfare perspective. A scenario in which a female leads a long reproductive life, but leaves the herd because of structural injury or death may fit optimization in a purely economic model but is undesirable from an animal welfare perspective. Thus, understanding and managing factors that contribute to involuntary culling is also important to both economic and animal well-being goals.

Staider et al. (2004) summarized a large body of literature published over the time period from 1960 to 2000 on factors that resulted in removal of sows from the breeding herd in commercial production systems. Reproductive failure was consistently the predominant category (ranging from 8.8 to $39.2 \%$ removed), but significant percentages of females were also removed because of feet, leg and locomotion problems (ranging from 6.1 to $15 \%$ ) and 
death (ranging from 3.0 to $12.3 \%$ ). The tendency in these same reports was for reproductive failure and feet and leg soundness to be a likely cause of removals at early parities, and for poor performance (presumably piglet output) or death to be a frequent cause for removal at later parities. Among the mortalities, arthritis, mastitis, cystitis, gastritis, heart failure and gastric torsion each accounted for significant proportions in specific populations. The same general predominance of reproductive failure, and tendency for changes in cause for removal as parity increases, has also been reported in more recent studies (Arango et al. 2005; Mote et al. 2009). In addition, recent summaries of commercial performance in United States systems include similar rates of sow mortality (PigCHAMP, 2007; overall average $-8.74 \%$, bottom $10 \%$ of herds average $=12.5 \%$ ).

\section{Genetic variation and selection for lifetime performance}

Genetic improvement of sow prolificacy has traditionally been focused on the component traits with known economic value that are most readily and routinely measured, primarily number of piglets produced in a litter. Significant differences between breeds and lines for litter traits can be the basis for relatively rapid changes in prolificacy and have been reported extensively dating back to the breed evaluation and crossbreeding studies coordinated in the US through regional research projects (Craft 1953, Johnson 1981). Even greater between-line variation in domestic swine was observed in breed evaluations after the importation of Chinese breeds into the US (Young 1995, Rothschild \& Bidanel 1998). More recently, evaluation of commercial crosses for reproductive output through four parities has been reported (Moeller et al. 2004); the range of averages for number born alive across the six commercial crosses tested was 1.45 piglets per litter.

Within-line genetic variance in litter size traits has also been suggested for many years as a means for genetic improvement of sow prolificacy (e.g., Dickerson \& Hazel 1944). Although the heritabilities for total number born and number born alive tend to be low (average 0.11 and 0.09, respectively; Rothschild \& Bidanel 1998), large phenotypic coefficients of variation provide the potential for genetic progress. Early attempts at controlled, direct selection for litter size in pigs were relatively unsuccessful (Rutledge 1981, Bolet et al. 1989), but selection on estimated breeding values for litter size traits in both males and females (Avalos \& Smith 1987) has become standard practice in industry nucleus herds and has resulted in significant increases in piglets born per litter.

Selection for biological components of litter size has also been pursued as a way for efficient genetic improvement of litter output (Johnson et al. 1984, Christenson et al. 1987). Direct selection for litter size was successful in a line of pigs previously selected for greater ovulation rate (Lamberson et al. 1991), suggesting that the previous selection had created a line in which ovulation rate was no longer a limiting factor on average and that subsequent selection for number born was effective by putting upward pressure on uterine capacity. Selection on an index of ovulation rate and embryo survival to day 50 of gestation, index selection followed by direct selection for litter size, and two-stage selection for ovulation rate followed by number born, have each been demonstrated to effectively improve number of live piglets born per litter in a long-term selection experiment at the University of Nebraska (Johnson et al. 1999, Ruiz-Flores \& Johnson 2001, Petry \& Johnson 2004).

Only recently have similar estimates of between- and within-line genetic variance in sow lifetime prolificacy traits been reported, and reports of correlated responses in lifetime reproductive performance to selection for first parity litter traits have been limited. There have been no reports in the scientific literature of response to selection for sow lifetime prolificacy. 
The evaluation of six commercial maternal lines for reproductive performance through parity four (Moeller et al. 2004) was extended to six parities in an effort to estimate between-line differences in sow longevity (Serenius et al. 2006). Removal from the project through parity four only occurred if a female failed to conceive within 50 days after weaning, was culled by a veterinarian because of health, or died. Of 3,251 total gilts studied, 17\% had right-censored data because they lived longer than six parities. Results from a survival analysis revealed that sows from one of the six maternal products lines had a significantly less risk of being removed from the herd than sows from the other five product lines, which were similar in survival distributions. On average, the five lines similar in longevity had 1.43 times greater risk of being culled than the line with lowest risk. The product line with lowest risk for culling was also the line with greatest number born alive per litter in the first four parities (Moeller et al. 2004). The previously described work on development of economic models for sow longevity by Rodriguez-Zas et al. (2003) also revealed significant differences between commercial maternal lines in average parity at culling (range of between-line averages $=1.05$ parity). These reports suggest that relatively rapid changes in sow longevity and lifetime prolificacy can be made by exploiting between-line variation.

Methods applied to analyses of within-line genetic variance have included use of linear models to length of productive life or binary $(0 / 1)$ records of survival to a given point in time ("stayability" to a given parity). Alternatively, to account for the inherent censored nature of lifetime data, survival analyses have been applied based on proportional hazard models. While survival analysis methods are more attractive from a theoretical perspective, there have not been practical methods to extend beyond univariate analysis of right-censored survival traits. More recently, methods have been reported for multivariate analyses of Gaussian (normallydistributed), right-censored Gaussian, ordered categorical and binary traits (Korsgaard et al. 2003; Damgaard \& Korsgaard 2006), thereby allowing for modeling of genetic and environmental correlations and hence the potential for more accurate estimation of parameters, breeding values and predicted responses to selection for lifetime traits.

A review by Serenius \& Stalder (2006) included a summary of estimates of within-line genetic variance for traits of sow longevity and productive life. Average heritability for length of productive life was 0.13 and 0.17 , respectively, when linear and survival models were applied, and average heritability for stayability was 0.08 . Serenius et al. (2008) used a multivariate Bayesian approach based on Korsgaard et al. (2003) in a subsequent study of Finnish Landrace national field records and reported a heritability of 0.22 for length of productive life. The categories for sow removal reported by Arango et al. (2005) were the basis for estimation of genetic variances using a linear censored model. Estimated heritabilities for the categories of removal due to reproductive, non-reproductive, and other reasons were $0.18,0.13$, and 0.15 , respectively. In total, these reports of within-line genetic variation for sow longevity and lifetime performance in current industry populations indicate that there exists the potential for response to effective genetic selection.

Some of the challenges that exist in genetic improvement of output per litter may also apply to selection for lifetime prolificacy. In addition to the generally low heritability for litter size and number born alive, selection accuracy is reduced because the traits are expressed only in females and at an age that is typically after selection decisions are made. Hence, selection is based largely on pedigree information. These barriers to accurate selection also certainly apply to sow lifetime reproductive performance.

Unfavorable correlations between direct genetic effects for traits of prolificacy and market pig performance also present a challenge to breeders to optimize selection emphasis on these trait areas and maximize genetic trend in profitability. Although much of the early literature 
reported non-significant genetic correlations between litter traits in early parities and growth performance, estimates of correlations and correlated responses to selection in more modern populations indicate unfavorable associations (Clutter \& Brascamp 1998, Holm et al. 2004). The review by Serenius \& Stalder (2006) of parameter estimates associated with sow lifetime performance also suggested unfavorable relationships with market pig traits. Average genetic correlations of stayability or length of productive life with leg conformation, litter size, average daily gain and backfat thickness were $0.13,0.26,-0.15$ and 0.14 , respectively. They suggested based on this summary that leg conformation and litter size could be used as early indicators of longer productive life, but questioned if the relationship between litter size and longevity was an autocorrelation due to culling for small litter size.

A negative daughter-dam regression has been widely reported in swine, in which females from large litters tend to produce litters of below average size (Revelle \& Robison 1973, Rutledge 1980), leading to recommendations for standardization of litter size in selection herds (e.g., Van Der Steen 1985) and estimation of both maternal genetic and additive genetic effects (Roehe \& Kennedy 1993) to achieve greatest response to selection. Negative correlations between maternal and direct effects on growth and efficiency have also been reported in swine (Robison 1972) and maternal effects on growth in swine and litter-bearing laboratory animals have been reported to extend to ages far beyond weaning (Clutter et al. 1996, Johnson et al. 2002). Foxcroft et al. (2006) describe a process through which intrauterine competition in highly prolific females results in a reduced number of muscle fibers by day 90 of gestation that may cause a permanent retardation of growth in surviving offspring. Population studies designed to quantify associations of maternal environment with subsequent growth, development and lifetime reproduction of offspring are needed to more fully and clearly understand these phenomena in the context of lifetime performance, and to better optimize lifetime reproduction and efficient lean meat production in commercial breeding strategies. The extent of linkage disequilibrium in the pig along with availability of densely-spaced, genome-wide markers (Du et al. 2007, Rothschild 2009) now also provides the opportunity to map the genetic architecture underlying these genetic variances and covariances by genotyping pedigreed populations that have had relevant phenotypes recorded.

An additional factor that must be considered when collecting new, or using historical, lifetime reproduction data from commercial pig populations is the amount of intentional emphasis put on sow replacement as a means of shortening generation interval and thereby accelerating genetic progress, versus culling of females from the breeding herd based purely on commercial profit drivers. Serenius et al. (2008) discussed the large amount of variation due to farm-year effects in the Finnish field dataset that they analyzed and suggested the usefulness of estimates of those effects over time as a management tool, but it is not clear in general how well the current statistical tools being applied to sow lifetime traits account for variation in censoring due to different culling policies among farms. These intentions may be more readily discernable in systems that have well-defined genetic nucleus, multiplier and commercial segments, than in systems in which the functions are less distinct, but in either case this factor must be accounted for adequately if useful estimation of genetic parameters is to be achieved. Moreover, this inherent conflict in a genetic nucleus herd between generation interval and expression of lifetime reproductive performance adds another level of challenge to genetic selection for a sex-limited trait that takes significant time to express, by requiring that the trait also be measured outside the genetic nucleus in animals more genetically distant to selection candidates. 


\section{An alternative for estimation of genetic merit in commercial breeding systems}

The desire to minimize the risk of new pathogens in commercial pork production systems by limiting the introduction of live animals, and minimize the genetic lag between genetic nucleus and commercial herds, has resulted in the widespread implementation of maternal multiplier systems in which, after the system is initially populated with females, only semen is introduced.

This structure may create a pedigreed population in which one segment is part of a genetic nucleus herd subject to intentionally high female replacement rates as a means of rapid generation turnover, and another segment has the goal of multiplication and female replacement is typical of commercial production. In this latter segment, sow lifetime performance can be expressed and recorded.

In Fig. 1 is a scheme for one such system that exists at Newsham Choice Genetics (NCG) and some of its customers. At the top of the pyramid at NCG are two distinct, closed Landrace nucleus populations (Internal Genetic Nucleuses GN-LR1 and GN-LR2). For any of these customers, an initial population of females from GN-LR1 is used to create an external nucleus (EGN-LR1), after which that multiplier is closed to new animal introductions. A proportion of the EGN-LR1 females each week are bred with semen from GN-LR1, and the remaining matings of EGN-LR1 females that week is with semen from GN-LR2. Thus, enough LR1 1 LR1 matings are made to produce candidate females for replacement to maintain the EGN-LR 1 , and the remainder of the matings are made to produce LR2 $\times$ LR1 litters. Selected females from the LR2 x LR1 litters ("LR3") are bred with semen from a Large White line to produce parent-stock gilts for commercial production. A key point is that all EGN-LR1 females are fully pedigreed and genetically tied to GN-LR1.



Fig. 1 Schema for external multiplication of hybrid Landrace females (LR3) to be used in production of parent-stock commercial gilts. GN-LR1 is the closed genetic nucleus for Landrace population 1. GN-LR2 is the closed genetic nucleus for Landrace Population 2. EGN-LR1 depicts one of the external customer herds of Landrace 1 females that produces its own replacement females and LR3 females. 
The maximum parity achieved for 59,268 females across all EGN-LR 1 herds is summarized in Fig. 2a. These numbers include right-censored data (females stilt in the herd) and data from herds that have not fully matured (i.e., relatively new herds). In Fig. $2 \mathrm{~b}$ are the proportions of females in each of the categories for maximum parity achieved, both for GN-LR1 and EGNLR1 herds. These data provide a basis for estimation of genetic variance in sow lifetime traits in GN-LR1, and of genetic covariances between growth, body composition, and early parity litter traits measure in GN-LR1 and sow lifetime traits measured in EGN-LR1. In addition, estimated breeding values for sow lifetime prolificacy can be generated for GN-LR 1 animals through multitrait genetic evaluation and used in selection for sow lifetime reproductive performance.

A



B

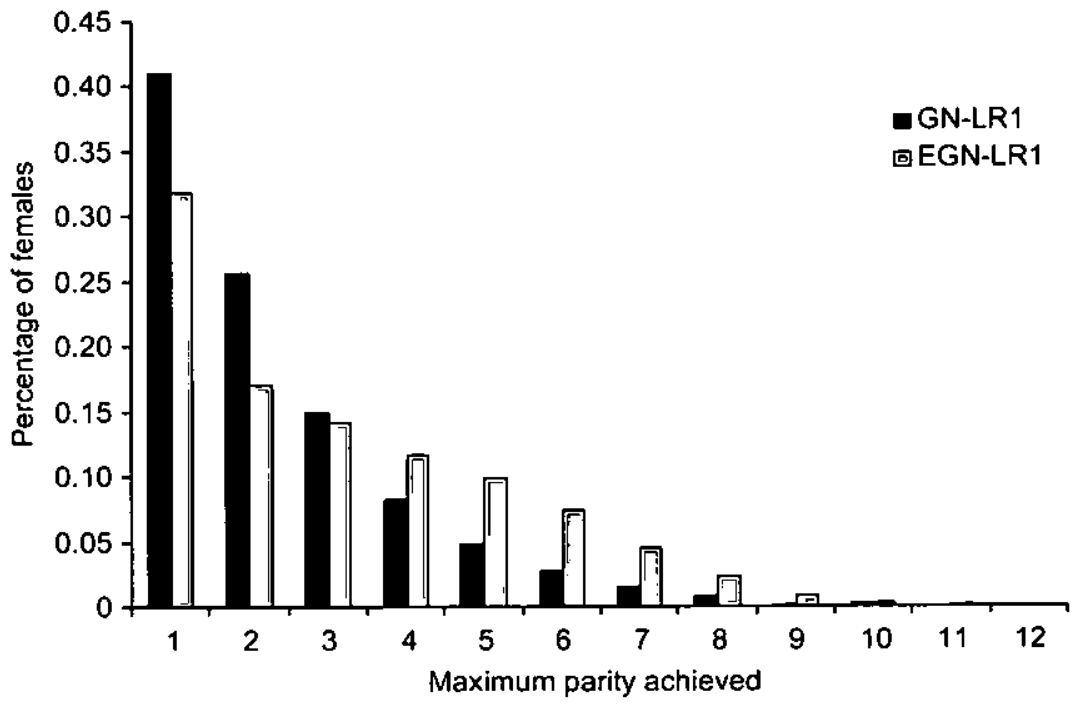

Fig. 2a-b The distribution of maximum number of parities achieved among sows from external herds of Landrace 1 in the multiplication system depicted in Fig. 1 (i.e., EGNLR1 herds): a) actual numbers of external herd females in each category; b) percentage of females in each category in external herds relative to the internal genetic nucleus for Landrace 1 (GN-LR1). 


\section{Conclusions}

Studies of the bioeconomics of sow lifetime performance reveal that selection goals for breeding programs in this area must emphasize not only longevity but consistent and prolonged reproductive output. Estimates of heritabilities for sow lifetime prolificacy indicate that genetic selection may be successful, but work remains to effectively overcome unfavorable genetic correlations that likely exist among traits in the overall profit function, as well as the challenge of how best to measure a commercial lifetime trait for use in selection within a genetic nucleus population. Commercial multiplier systems with direct genetic and record-keeping ties to genetic nucleus herds may provide a framework for more accurate parameter estimation and practical selection tools.

\section{References}

Arango J, Misztal I, Tsuruta S, Culbertson $M$ \& Herring W 2005 Study of codes of disposal at different parities of Large White sows using a linear censored model. Journal of Animal Science 83 2052-2057.

Avalos E \& Smith C 1987 Genetic improvement of litter size in pigs. Animal Production 44 153-163.

Bolet G, Ollivier L \& Dando P 1989 Selection sur la prolificite chez le porc. I. Resultats d'une experience de selection sur onze generations. Cenetics Selection and Evolution 21 93-106.

Burt OR 1965 Optimal replacement under risk. Journal of farm Economics 47 324-346.

Christenson RK, Leymaster KA \& Young LD 1987 Justification of unilateral hysterectomy-ovariectomy as a model to evaluate uterine capacity in swine. Journal of Animal Science 65 738-744.

Clutter AC \& Brascamp EW 1998 Genetics of performance traits. In The Cenetics of the Pig, Edited by Rothschild MF \& Ruvinsky A, CAB International.

Clutter AC, Pomp D \& Murray JD 1996 Quantitative genetics of transgenic mice: Components of phenotypic variation in body weights and gains. Cenetics 143 1753-1760.

Craft WA 1958 Fifty years of progress in swine breeding. fournal of Animal Science 17 960-980.

Damgaard LH \& Korsgaard IR 2006 A bivariate quantitative genetic model for a linear Gaussian trait and a survival trait. Genetics Selection and Evolution 38 45-64.

Dickerson GE \& Hazel LN 1944 Selection for growth rate of pigs and productivity of sows. Journal of Animal Science 3 201-212.

Du FX, Clutter AC \& Lohuis MM 2007 Characterizing linkage disequilibrium in pig populations. International Journal of Biological Sciences 3(3) 166-178.

Foxcroft GR, Dixon WT, Novak S, Putman CT, Town SC \& Vinsky MDA 2006 The biological basis for prenatal programming of postnatal performance in pigs. Journal of Animal Science 84 (E Supplement) E105-E112.

Huirne RBM, Dijkhuizen AA \& Renkema JA 1991 Economic optimization of sow replacement decisions on the personal computer by method of stochastic dynamic programming. Livestock Production Science 28 331-347.
Holm B, Bakken M, Klemetsdal G \& Vangen O 2004 Genetic correlations between reproduction and production traits in swine. Journal of Animal Science 82 3458-3464.

Johnson RK 1981 Crossbreeding in swine: Experimental results. Journal of Animal Science 52 906-923.

Johnson RK, Zimmerman DR \& Kittok RJ 1984 Selection for components of reproduction in swine. Livestock Production Science 11 541-558.

Johnson RK, Nielsen MK \& Casey DS 1999 Responses in ovulation rate, embryo survival, and litter traits in swine to 14 generations of selection to increase litter size. Journal of Animal Science 77 541-557.

Johnson ZB, Chewning J] \& Nugent RA III 2002 Maternal effects on traits measured during postweaning performance test of swine from four breeds. Journal of Animal Science 80 1470-1477.

Korsgaard IR, Lund MS, Sorensen D, Gianola D, Madsen P \& Jensen / 2003 Multivariate Bayesian analysis of Gaussian, right censored Gaussian, ordered categorical and binary traits using Gibbs sampling. Genetics Selection and Evolution 35 159-183.

Lamberson WR, Johnson RK, Zimmerman DR \& Long TE 1991 Direct responses to selection for increased litter size, decreased age at puberty, or random selection following selection for ovulation rate in swine. fournal of Animal Science 69 3129-3143.

Moeller SJ, Goodwin RN, Johnson RK, Mabry JW, Baas TJ \& Robison OW 2004 The National Pork Producers Council Maternal Line National Genetic Evaluation Program: A comparison of six maternal genetic lines for female productivity measures over four parities. Journal of Animal Science 82 41-53.

Mote BE, Mabry JW, Stalder KJ \& Rothschild MF 2009 Evaluation of current reasons for removal of sows from commercial farms. Professional Animal Scientist (in press).

Petry DB \& Johnson RK 2004 Responses to 19 generations of litter size selection in the Nebraska Index line. I. Reproductive responses estimated in pure line and crossbred litters. Journal of Animal Science $\mathbf{8 2}$ 1000-1006.

Revelle TJ \& Robison OW 1973 An explanation for the 
low heritability of litter size in swine. Journal of Animal Science 37 668-675.

Robison OW 1972 The role of maternal effects in animal breeding: $V$. Maternal effects in swine. Journal of Animal Science 35 1303-1315.

Rodriguez-Zas SL, Southey BR, Knox RV, Connor JF, Lowe JF \& Roskamp B) 2003 Bioeconomic evaluation of sow longevity and profitability. Journal of Animal Science 81 2915-2922.

Rodriguez-Zas SL, Davis CB, Ellinger PN, Schnitkey GD, Romine NM, Connor JF, Knox RV \& Southey BR 2006 Impact of biological and economic variables on optimal parity for replacement in swine breed-to-wean herds. Journal of Animal Science 84 2555-2565.

Roehe R \& Kennedy BW 1993 The influence of maternal effects on accuracy of evaluation of litter size in swine. Journal of Animal Science 71 2353-2364.

Rothschild MF 2009 Swine genetic challenges of the future: One man's thoughts. Proceedings of the Annual Meeting of the National Swine Improvement Federation (hitp://www.nsif.com).

Rothschild MF \& Bidanel JP 1998 Biology and genetics of reproduction. In The Cenetics of the Pig, edited by Rothschild MF \& Ruvinsky A, CAB International.

Ruiz-Flores A \& Johnson RK 2001 Direct and correlated responses to two-stage selection for ovulation rate and number of fully formed pigs at birth in swine. Journal of Animal Science 79 2286-2297.

Rutledge J| 1980 Fraternity size and swine reproduction. II. Genetic consequences. Journal of Animal Science 51 871-874.

Serenius T \& Stalder KJ 2006 Selection for sow longevity. Journal of Animal Science 84 (E Supplement) E166-E171.
Serenius T, Stalder KJ, Baas TI, Mabry IW, Goodwin RN, Johnson RK, Robison OW, Tokach M \& Miller RK 2006 National Pork Producers Council Maternal Line National Genetic Evaluation Program: A comparison of sow longevity and trait associations with sow longevity. Journal of Animal Science 84 2590-2595.

Serenius T, Stalder KJ \& Fernando RL 2008 Genetic associations of sow longevity with age at first farrowing, number of piglets weaned, and wean to insemination interval in the Finnish Landrace swine population. Journal of Animal Science 86 3324-3329.

Stalder KJ, Lacy RC, Cross TI \& Conatser GE 2003 Financial impact of average parity of culled females in a breed-to-wean swine operation using replacement gilt net present value analysis. Journal of Swine Health and Production 11 69-74.

Stalder KJ, Knauer M, Baas T), Rothschild MF \& Mabry IW 2004 Sow Longevity. Pig News and information 25 53N-74N.

Tess MW, Bennett GI. \& Dickerson GE 1983 Simulation of genetic changes in life cycle efficiency of pork production. II. Effects of components on efficiency. Journal of Animal Science 56 354-368.

Van Der Steen HAM 1985 The implication of maternal effects on genetic improvement of litter size in pigs. Livestock Production Science 13 159-168.

Young LD 1995 Reproduction of F1 Meishan, Fengjing, Minzhu and Duroc gilts and sows. Journal of Animal Science 73 711-721.

Young LD, Johnson RK \& Omtvedt IT 1977 An analysis of the dependency structure between a gilt's prebreeding and reproductive traits. II. Principal component analysis. Journal of Animal Science 44 565-570. 